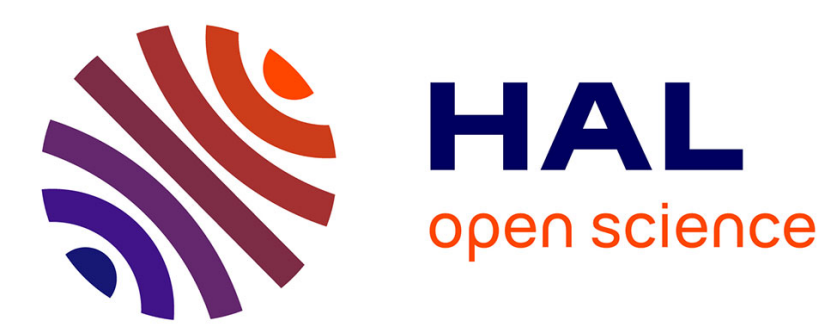

\title{
Oxidative cyclization of linoleic acid in the presence of hydrogen peroxide and phosphotungstic acid
}

Nahla Araji, Gregory Chatel, Audrey Moores, François Jerome, Karine de Oliveira Vigier

\section{- To cite this version:}

Nahla Araji, Gregory Chatel, Audrey Moores, François Jerome, Karine de Oliveira Vigier. Oxidative cyclization of linoleic acid in the presence of hydrogen peroxide and phosphotungstic acid. Molecular Catalysis, 2020, 493, pp.111084. 10.1016/j.mcat.2020.111084 . hal-03015077

\section{HAL Id: hal-03015077 https://hal.science/hal-03015077}

Submitted on 19 Nov 2020

HAL is a multi-disciplinary open access archive for the deposit and dissemination of scientific research documents, whether they are published or not. The documents may come from teaching and research institutions in France or abroad, or from public or private research centers.
L'archive ouverte pluridisciplinaire HAL, est destinée au dépôt et à la diffusion de documents scientifiques de niveau recherche, publiés ou non, émanant des établissements d'enseignement et de recherche français ou étrangers, des laboratoires publics ou privés. 


\section{Oxidative cyclization of linoleic acid in the presence of hydrogen}

\section{peroxide and phosphotungstic acid}

Nahla Araji, ${ }^{a}$ Gregory Chatel,,${ }^{b,}$ Audrey Moores,${ }^{c,}{ }^{*}$ François Jérôme, ${ }^{a}$ Karine De Oliveira $\operatorname{Vigier}^{a, *}$

aC2MP, UMR CNRS 7285-Université de Poitiers, France, ENSIP, B1, 1 rue Marcel Doré, TSA 41105, 86073 Poitiers Cedex 9, France. karine.vigier@univ-poitiers.fr

b Univ. Savoie Mont Blanc, LCME, F-73000 Chambéry, France. Gregory.Chatel@univsmb.fr

${ }^{\mathrm{c}}$ Centre for Green Chemistry and Catalysis, Department of Chemistry, McGill University, 801 Sherbrooke St. West, Montreal, H3A0B8, Quebec, Canada. audrey.moores@mcgill.ca

\section{$\underline{\text { Abstract: }}$}

The synthesis of THF and tetrahydro-2H-pyrane is of interest due to the applications of such molecules as antitumour, pesticidal, antiprotozoal and antimicrobial agents for instance. Here, an original approach was performed to prepare these derivatives starting from linoleic acid in the presence of hydrogen peroxide and phosphotungstic acid in the absence of a phase transfer agent. A maximum cyclic compounds yield of $99 \%$ was obtained under mild conditions of temperature. A heterogeneous catalyst was synthesized by exchanging proton by Cs to obtain $\mathrm{Cs}_{2,3} \mathrm{H}_{0,7} \mathrm{PW}_{12} \mathrm{O}_{40}$ that was recycled up to 3 cycles. It is one of the best yield to these products observed in the literature from fatty acids.

KEYWORDS: linoleic acid; heteropolyacids; tungsten catalyst; hydrogen peroxide; THF derivatives. 


\section{$\underline{\text { 1. Introduction }}$}

Nowadays, vegetable oils are used as renewable raw materials for the manufacture of industrial products such as biofuels, lubricants, surfactants and pharmaceutical and cosmetic products [1]. To access these products, vegetable oils undergo chemical treatments such as hydrolysis, transesterification, oxidation, hydrogenation, metathesis, etc [2]. The presence of one or more $\mathrm{C}=\mathrm{C}$ double bonds in the fatty chain of these molecules provides a chemical manifold and makes their functionalization a center of interest for several domains such as polymer synthesis, cosmetics and others. Hydroxylation reactions can led to vicinal alcohols which are an interesting class of molecules in the formulation of several products, such as paints, surface coating, food emulsifiers, soap surfactants, biofuel additives, etc. [3]. These vicinal alcohols also act as an intermediate for the production of dicarboxylic acids such as azelaic and pelargonic acids, which are valuable specialty monomers [4]. In the literature, the hydroxylation of polyunsaturated fatty esters is generally followed by a cyclization process leading to the formation of substituted tetrahydrofurans (THFs). These compounds are of interest due to their biological activity in areas such as polyether antibiotics and Annonaceous acetogenins [5-6]. Hence, Annonaceous acetogenins constituted of THF and Tetrahydro-2H-pyrane derivatives are bioactives as antitumour, immunosuppressive, pesticidal, antiprotozoal, antifeedant, anthelmintic and antimicrobial agents. Several acetogenins were isolated such as 4-acetyl gigantetrocin A [7], 4-acetyl annonacin [8] and 4-acetyl xylomaticin [8], annohexocin [9] and murihexocins [10]. The synthesis of these types of molecules via oxidative cyclization of fatty acid methyl ester such as linoleic acid has been little investigated. Yet it is a desirable approach with benefits for simplicity and atom-economy if developed with green catalysts. 
Travis et al. [11] investigated the oxidative cyclization of methyl linoleate and methyl arachidonate in a reaction medium containing tetrahydrofuran (THF), water and perchloric acid $\left(\mathrm{HClO}_{4}\right)$. Furanic isomers (five-membered ring) were formed (Scheme 1) through a cascade epoxidation/hydrolysis reaction (30\% yield).

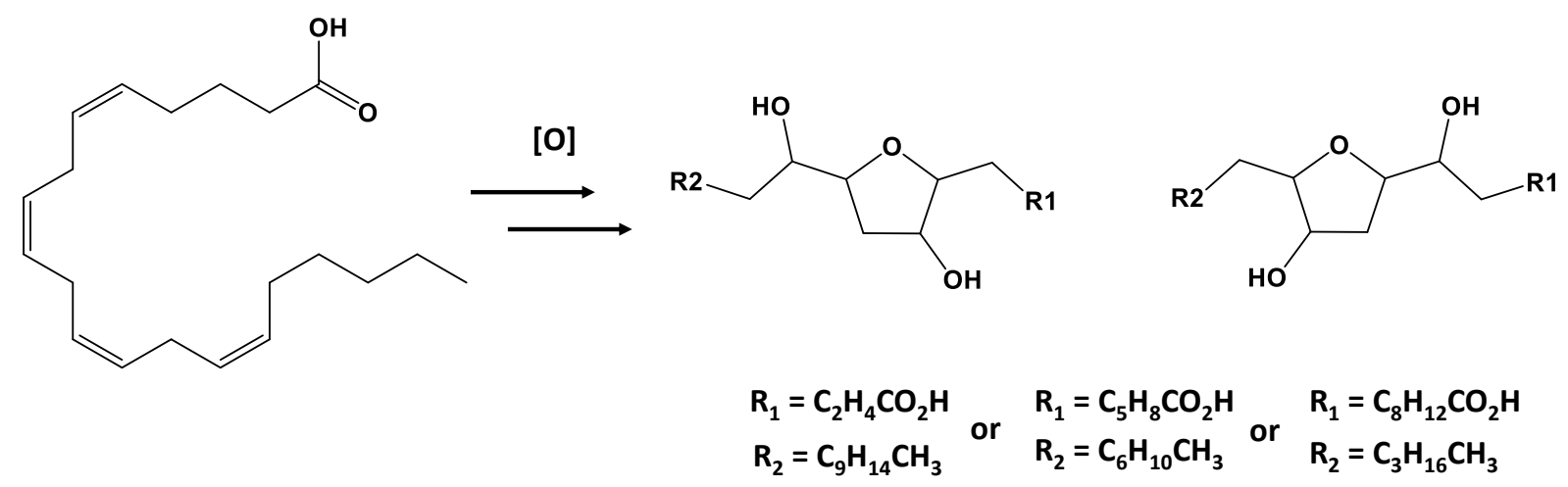

Scheme 1. Formation of 2,3,5-THF-tri-substituted diols from arachidonic acid [19].

In another study, several oxidant systems $\left(\mathrm{KMnO}_{4}, \mathrm{OsO}_{4}, \mathrm{RuCl}_{3}\right)$ were studied for the oxidative cyclisation of fatty acids (arachidonic acid) and fatty acid esters (methyl linoleate) [12]. These oxidants led to low yields of furanic isomers (30\%) due to a competitive secondary oxidation reactions (fatty acid fragmentation). In addition, the oxidants used can be toxic, expensive and corrosive. Another interesting oxidant is hydrogen peroxide since the only byproduct formed during the $\mathrm{H}_{2} \mathrm{O}_{2}$ based oxidation reaction is water. In the literature, the hydroxylation of unsaturated fatty acids using $\mathrm{H}_{2} \mathrm{O}_{2}$ as oxidant was generally performed using tungsten catalytic systems based for examples on tungstic, phosphotungstic or pertungstic acids [13-15]. The main drawbacks of these approaches were the need for high concentrations of hydrogen peroxide (up to 70\%) and the use of a phase transfer agent. Another important challenge for successful hydroxylation reactions is the control of the selectivity toward the desired product, since several molecules can be obtained such as epoxides, diols or compounds resulting from the oxidative cleavage [16-18]. 
Herein, we report the selective oxidative cyclization (hydroxylation/cyclization) of linoleic acid to tetrahydrofuran (1 and 2) and tetrahydro-2H-pyrane (3) derivatives in the presence of hydrogen peroxide and phosphotungstic acid as depicted on Scheme 2. The experimental conditions were optimized in order to obtain a high yield in cyclic isomers. A heterogeneous form of $\mathrm{H}_{3} \mathrm{PW}_{12} \mathrm{O}_{40}$ was synthesized $\left(\mathrm{Cs}_{2,3} \mathrm{H}_{0,7} \mathrm{PW}_{12} \mathrm{O}_{40}\right)$, and the recyclability of this catalytic system was studied. To the best of our knowledge, this is the first time that these cyclic compounds were obtained with high yield (99\%) from fatty acids with an atom economical and safe oxidant, in absence of a phase transfer agent.
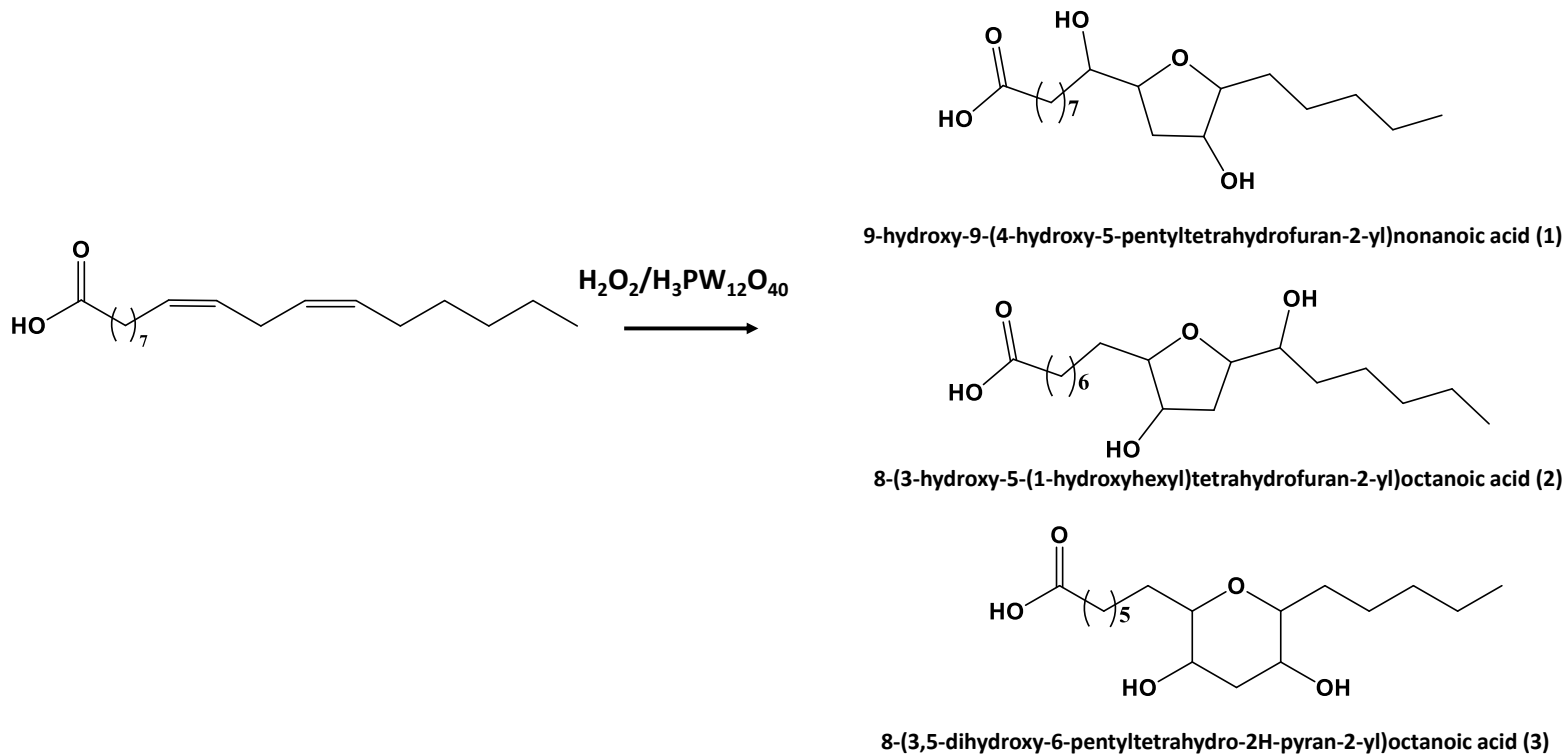

Scheme 2. Conversion of linoleic acid to substituted THF and Tetrahydro-2H-pyrane.

\section{Experimental part}

\subsection{Materials and methods}

Hydrogen peroxide (30 wt.\%) purchased from Acros-Organics was the oxidant used for all reactions. Linoleic acid was purchased from Sigma Aldrich with a purity of 99\% (Figure S1) and phosphotungstic acid $\mathrm{H}_{3} \mathrm{PW}_{12} \mathrm{O}_{40}$ from Sigma-Aldrich, was used as an acid catalyst.

\subsection{Synthesis of $\mathrm{Cs}_{2,3} \mathrm{H}_{0,7} P W_{12} \mathrm{O}_{40}$ catalyst}


The heterogeneous catalyst was synthesized by the exchange of 2.3 protons of $\mathrm{H}_{3} \mathrm{PW}_{12} \mathrm{O}_{40}$ by 2.3 Cs atoms from cesium nitrate according to the study of Gharib et al. (Scheme 3) [19].

$$
\mathrm{H}_{3} \mathrm{PW}_{12} \mathrm{O}_{40}+2.3 \mathrm{CsNO}_{3}------------>\quad \mathrm{Cs}_{2.3} \mathrm{PW}_{12} \mathrm{O} 40+3 \mathrm{HNO}_{3}
$$

Scheme 3. Synthesis reaction of $\mathrm{Cs}_{2 \cdot 3} \mathrm{H}_{0,7} \mathrm{PW}_{12} \mathrm{O}_{40}$.

To this aim, phosphotungstic acid $(1.0 \mathrm{mmol}, 2.9 \mathrm{~g})$ was introduced to $15 \mathrm{ml}$ of deionized water in a $50 \mathrm{ml}$ flask under magnetic stirring for $10 \mathrm{~min}$ at room temperature. An aqueous solution of cesium nitrate $(2.5 \mathrm{mmol}, 0.49 \mathrm{~g}$ in $4 \mathrm{ml}$ deionized water) was added drop by drop to the solution. A stirring was maintained for $24 \mathrm{~h}$ at room temperature. The white catalyst was recovered by filtration. The catalysts was washed several times with deionized water before being drying in an oven at $60{ }^{\circ} \mathrm{C}$ for $16 \mathrm{~h}$. The specific surface area was measured by $\mathrm{N}_{2}$ adsorption-desorption isotherms and was $123 \mathrm{~m}^{2} \cdot \mathrm{g}^{-1}$ accordingly to the literature [20]. The pore volume was $0.103 \mathrm{~cm}^{3} / \mathrm{g}$ and the pore size measured by BJH was $8.9 \mathrm{~nm}$. The acid sites of this catalyst was measured by $\mathrm{NH}_{3}$ TPD in the literature and was reported to be $161 \mu \mathrm{Lmol} \mathrm{g}^{-1}$ [21].

\subsection{Catalytic tests}

In a $50 \mathrm{ml}$ round flask, linoleic acid $(1.5 \mathrm{mmol}, 420 \mathrm{mg})$ was introduced with an amount of aqueous hydrogen peroxide (30 wt.\%, $1.5-3.5$ eq., $0.23-0.54 \mathrm{ml}$ ) to a specified amount of phosphotungstic acid (21-63 mg). The reaction medium was subsequently heated under reflux and kept under vigorous agitation. After reaction, ethyl acetate $(40 \mathrm{ml})$ was added to the reaction medium in order to solubilize and extract the organic phase. The organic phase was subsequently recovered and dried by adding sodium sulphate. After a filtration, the ethyl acetate was evaporated using a rotary evaporator. Before gas chromatography (GC) analysis, the sample was diluted using $1 \mathrm{ml}$ of pyridine and silylated by adding hexamethyldisilazane $(1 \mathrm{ml})$ and chlorotrimethylsylane $(1 \mathrm{ml})$. Sorbitol $(2 \mathrm{mg})$ used as external standard was added to the sample before analysis. 


\subsection{Analyses}

In our study, the analysis and quantification of linoleic acid and formed products were performed using a Varian 3900 gas chromatograph. The latter is equipped with a split/splitless injection port, a flame ionization detector (FID) and a BP5 column $(30 \mathrm{~m} \times 0.32 \mathrm{~mm} \times 1 \mu \mathrm{m})$ composed of a mixture of 5\% phenyl and 95\% dimethyl polysiloxane.

Linoleic acid conversion and products yields were calculated based on calibration curves and using the following equations:

$$
\begin{gathered}
\text { Conversion }(\%)=\frac{A_{\text {linoleic acid }}^{i} / A_{\text {sorbitol }}-A_{\text {linoleic acid }}^{t} / A_{\text {sorbitol }}}{A_{\text {linoleic acid }}^{i} / A_{\text {sorbitol }}} \times 100 \\
\text { Yield }(\%)=\frac{\text { mol.of products at } t}{\text { mol of linoleic acid at } t=0} \times 100
\end{gathered}
$$

Where $A_{\text {linoleic acid }}^{i}$ and $A_{\text {linoleic acid }}^{t}$ represent the values of the area of linoleic acid chromatographic peaks respectively at the initial time (time zero) and time of control (similarly for $A_{\text {product }}^{i}$ and $\left.A_{\text {product }}^{t}\right)$. $A_{\text {sorbitol }}$ is the area of the external standard.

The yields of reactive products were measured using ${ }^{1} \mathrm{H}$ NMR spectroscopy recorded on a $400 \mathrm{MHz}$ Bruker Avance DPX spectrometers for 9,12-diepoxystearic acid and by GC analysis for the substituted THF and terahydro-2H-pyrane derivatives. To this end, these products were synthesized from linoleic acid with a purity of $99 \%$ and used for calibration. The nature of the cyclic compounds were confirmed by ${ }^{1} \mathrm{H}$ NMR (Figure S2) and by mass spectrometry analysis using a Bruker Impact HD (Q-TOF) (Figure S3). Despite our efforts, we could not separate the three cyclic compounds by GC analysis, due to their similar polarity. Thus, a global yield of the three cyclic compounds was reported. 


\section{Results and discussion}

In a first set of experiments, the oxidative cyclization of linoleic acid $(1.5 \mathrm{mmol})$ was performed in the presence of 15 wt.\% of $\mathrm{H}_{3} \mathrm{PW}_{12} \mathrm{O}_{40}$ and 3.5 equivalents of $\mathrm{H}_{2} \mathrm{O}_{2}\left(30\right.$ wt. \%) at $80{ }^{\circ} \mathrm{C}$. After $2 \mathrm{~h}$ of reaction, a total conversion of linoleic acid was observed with the formation of two 5membered ring cyclic ethers (1 and 2) and one 6-membered ring one (3) with a total yield of $50 \%$ (Figure 1, Scheme 2).

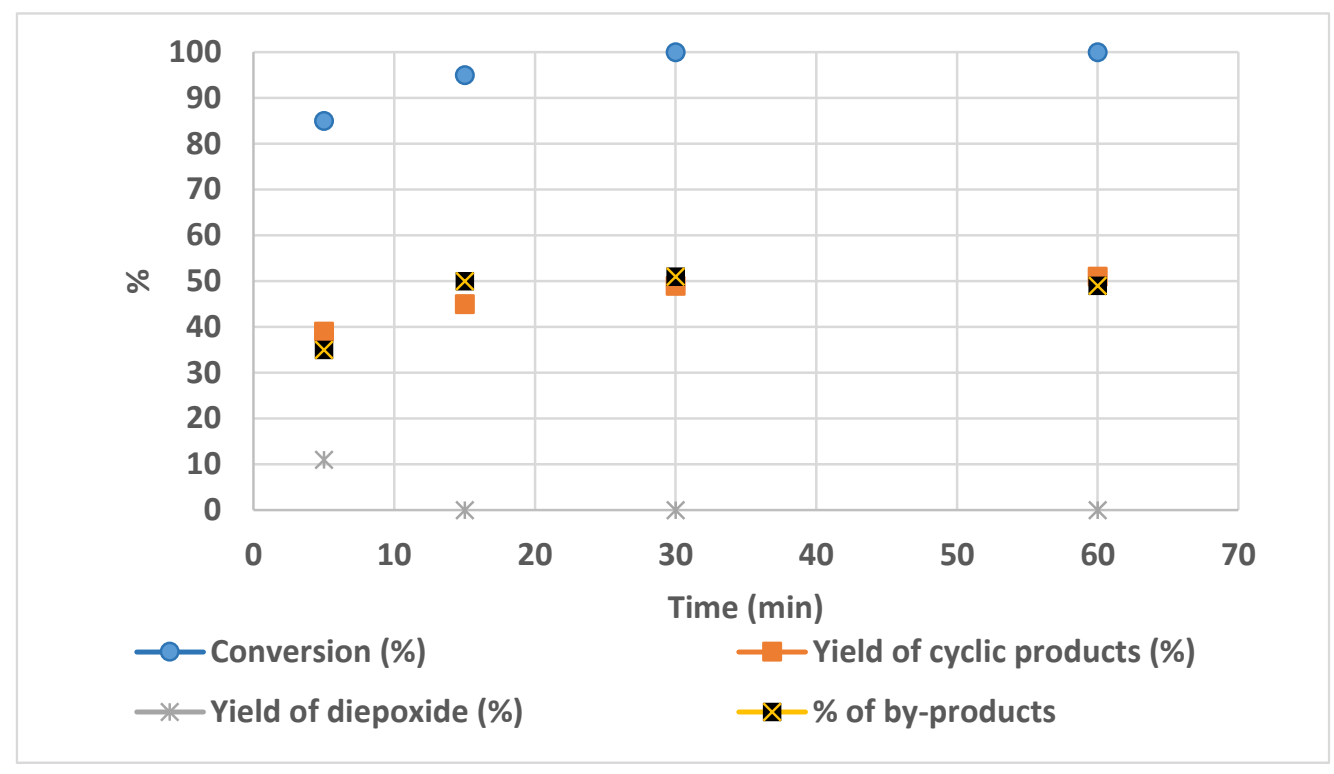

Figure 1. Kinetic profile of the conversion of linoleic acid $(1.5 \mathrm{mmol})$ as a function of time in the presence of 3.5 equivalents of $\mathrm{H}_{2} \mathrm{O}_{2}$ and 15 wt.\% of $\mathrm{H}_{3} \mathrm{PW}_{12} \mathrm{O}_{40}$ at $80{ }^{\circ} \mathrm{C}$.

Cyclic products were analyzed by ${ }^{1} \mathrm{H}$ NMR and MS analysis. The cyclic compounds were therefore synthesized by hydroxylating $1.5 \mathrm{mmol}$ of linoleic acid in the presence of $15 \mathrm{wt} . \%$ of phosphotungstic acid and 2.5 equivalents of $\mathrm{H}_{2} \mathrm{O}_{2}$ at $80{ }^{\circ} \mathrm{C}$ for $30 \mathrm{~min}$ of reaction. The purity of the synthesized products were measured using ${ }^{1} \mathrm{H}$ NMR spectroscopy and mass spectrometry as shown in Figures 2 and 3 respectively. On Figure 2, all the peaks correspond to the cyclic compounds and the non identified impurities present in linoleic acid as shown on Figure S1. 


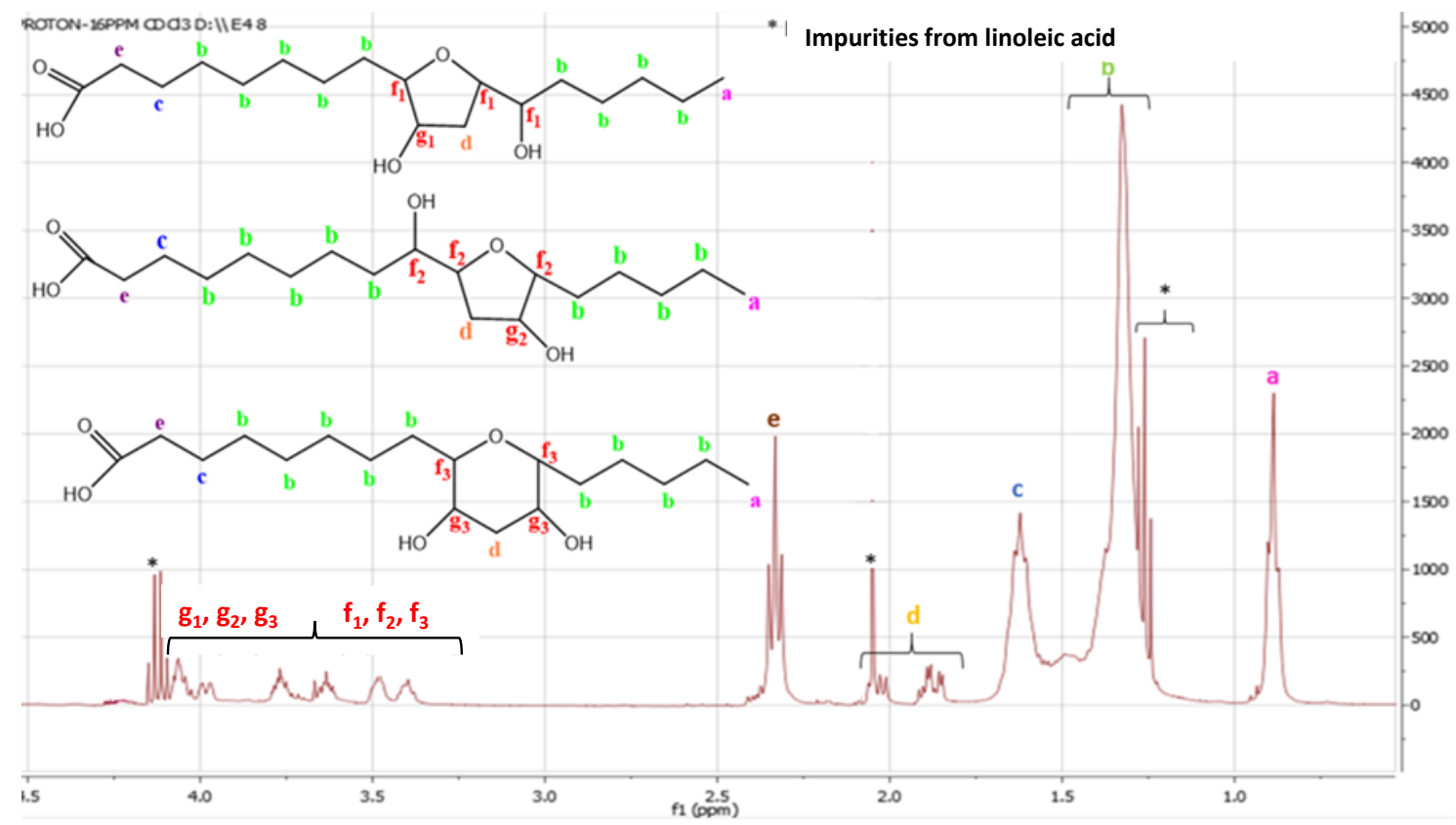

Figure 2. ${ }^{1} H$ NMR of the produced cyclic compounds.

There is one peak that corresponds to the cyclic compounds with a m/z of 353 with a Na adduct. Another peak at $\mathrm{m} / \mathrm{z}$ of 683 was observed corresponding to two diols sur to the high concentration of products used (Figure 3).

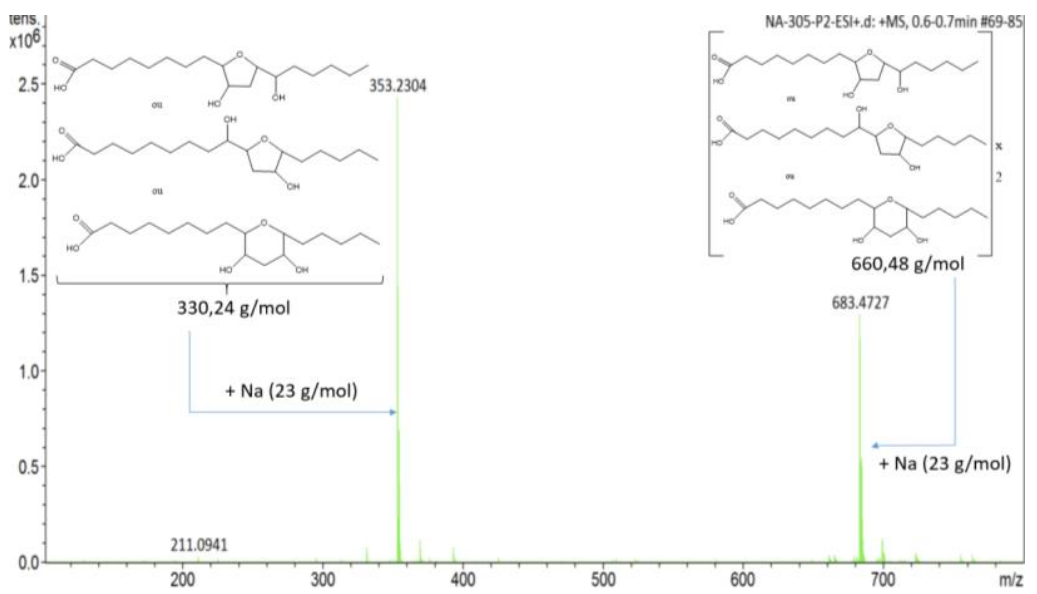

Figure 3. Mass spectrometry of the produced cyclic compounds.

To confirm that we these compounds are formed, ${ }^{13} \mathrm{C}$ NMR analysis was performed and we obtained the following spectra that corroborate cyclic compounds are formed (Figure 4). 


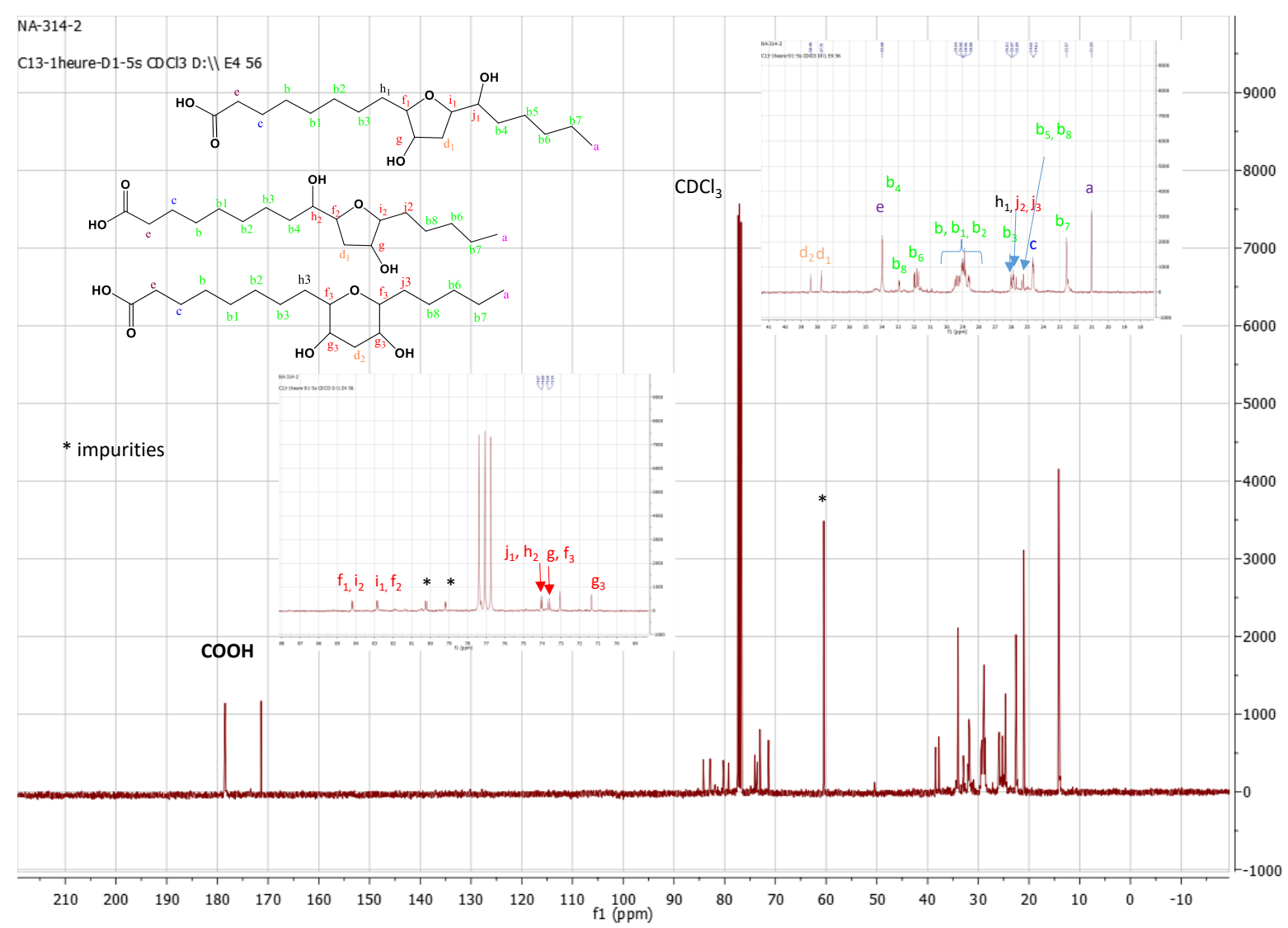

Figure 4. 13C NMR of products obtained.

The chemical shifts were attributed using prediction and the peaks are split due to the presence of diastereoisomers. A 2D-HSQC NMR analysis was also performed and confirm that cyclic compounds were formed as depicted on Figure 5. 


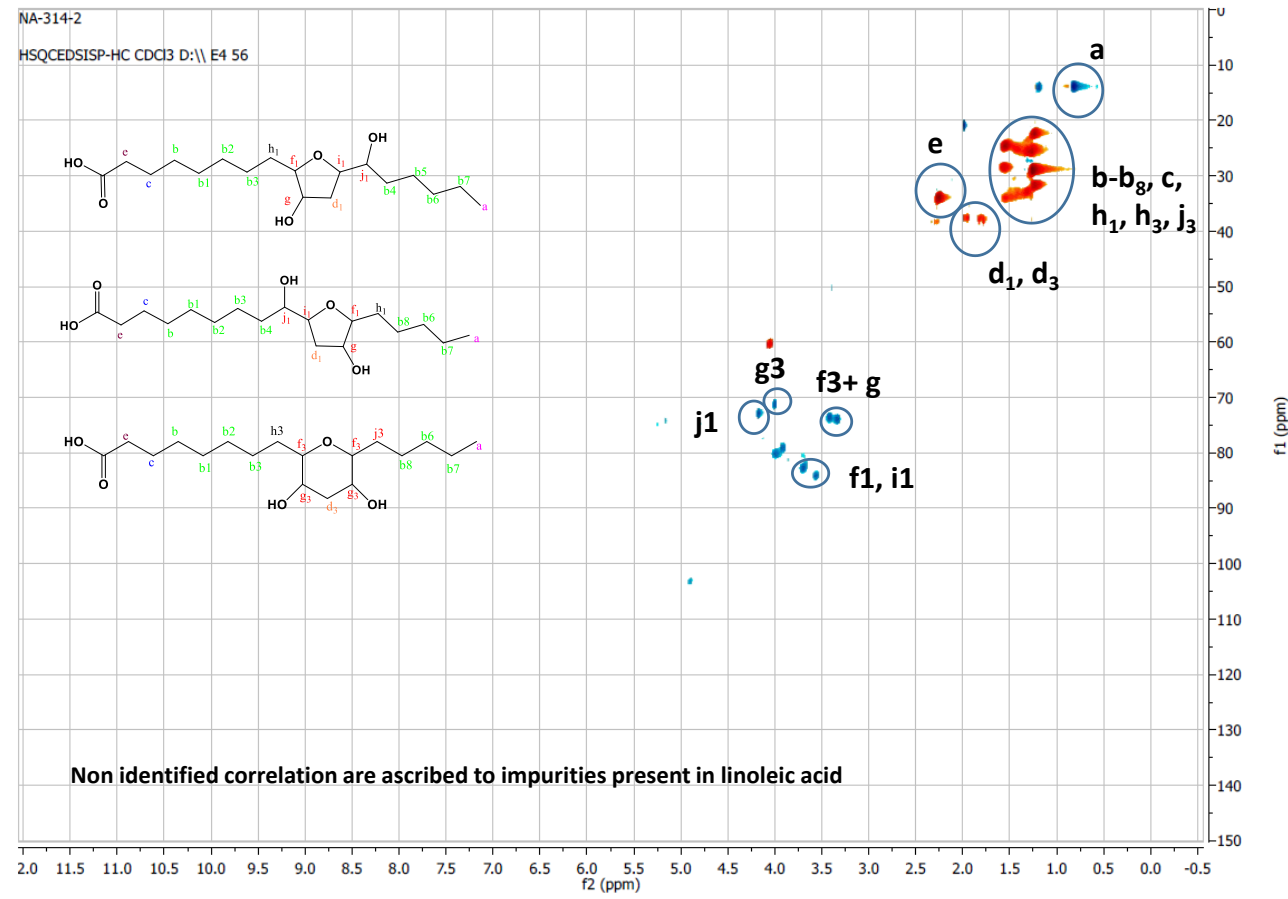

Figure 5. 2D HSQC NMR of products obtained.

Based on these analysis, the products were purified and they were analyzed by GC (Figure 6)

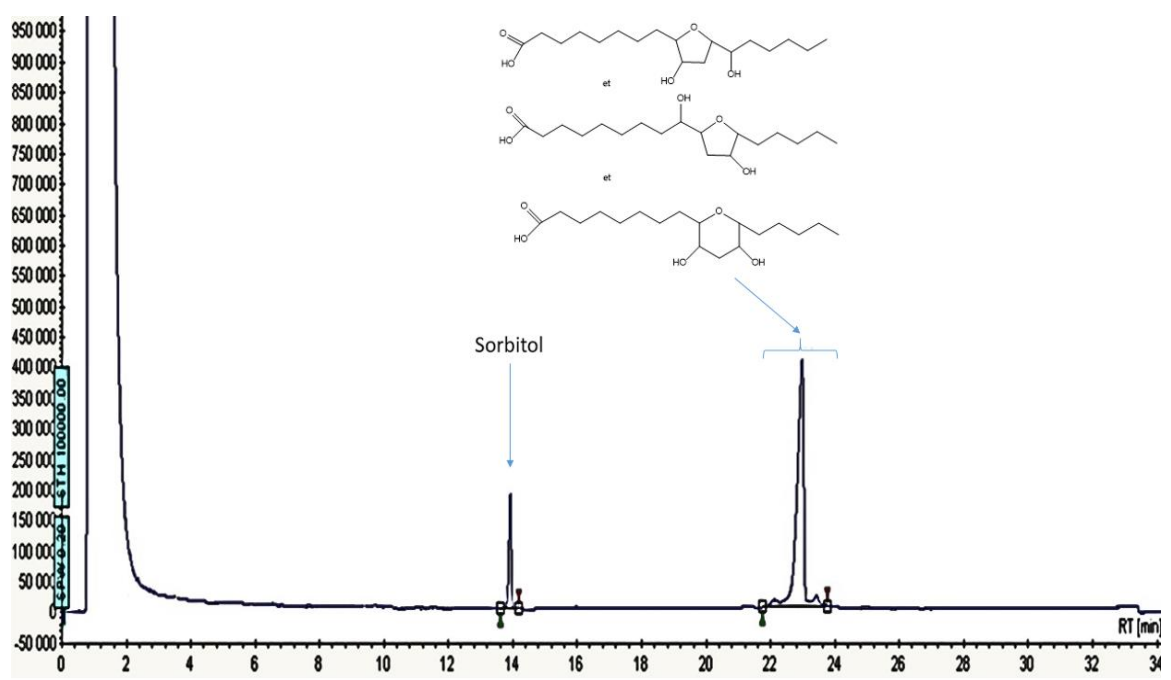

Figure 6. Chromatogram of the three cyclic isomers (sorbitol: internal standard)

A calibration was made (Figures S2 and S3) and all the yields provided are GC yields. Unfortunately we were not in a position to separate them by GC and quantify them individually. For the intermediate, 9,12-diépoxystearic acid was identified and quantified. Other products were also detected. Despite our effort to analyze these by-products, we were only able to 
identify one of them by mass spectroscopy analysis (Figure S4). A m/z of 195 was observed corresponding to the molecular weight of 9-oxononanoic acid and a sodium adduct (Scheme 4).

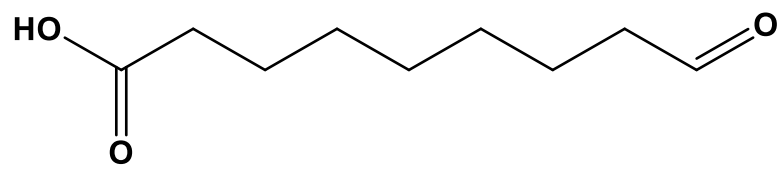

Scheme 4. Product resulting from the fragmentation of cyclic isomer: 1: 9-oxononanoic acid.

A kinetic profile was also carried out (Figure 1). After 5 min of reaction, $85 \%$ of linoleic acid was converted to the three cyclic compounds with a total yield of $39 \%$ and $46 \%$ of selectivity. Another product was formed corresponding to 9,12-diepoxystearic acid with a yield of 11\% (Scheme 5). By-products were also observed as reported on Figure 1. In all the presented results the missing percentage in yield is due to the formation of unidentified products.

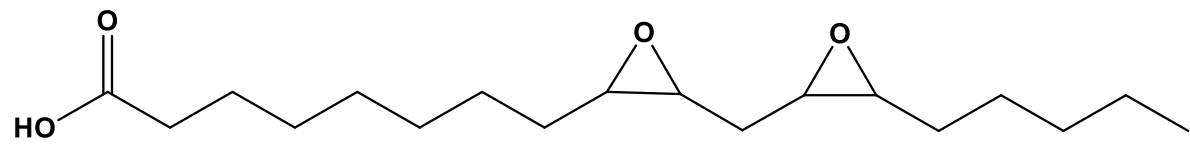

Scheme 5. Structure of 9,12-diepoxystearic acid.

After 15 min of reaction, the conversion of linoleic acid increased slightly to $95 \%$. In parallel, the yield of cyclic compounds increased from $39 \%$ to $45 \%$, while the yield of 9,12 diepoxystearic acid decreased from $11 \%$ to $0 \%$. A total conversion and a maximum yield in the cyclic compounds of $50 \%$ (50\% selectivity) were observed after $30 \mathrm{~min}$ of reaction. The decrease in the yield of 9,12-diepoxystearic acid from $11 \%$ to $0 \%$ can be due to its conversion to cyclic compounds or to its decomposition. Upon prolonged reaction time, the cyclic compounds selectivity did not change that can be due to the stability of the active species or to the lack of hydrogen peroxide in the reaction media. Additional studies were performed in order 
to improve yield and selectivity in cyclic isomers and also to determine if 9,12-diepoxysteraric acid is an intermediate in this reaction.

\subsection{Influence of the amount of hydrogen peroxide}

The first parameter studied was the amount of $\mathrm{H}_{2} \mathrm{O}_{2}$. The reaction was performed using similar conditions as before with different loading of $\mathrm{H}_{2} \mathrm{O}_{2}$ : 1.5 eq., 2.5 eq. and 3.5 eq. (Table 1 ). $\mathrm{A}$ decrease in the quantity of hydrogen peroxide from 3.5 to 2.5 eq. led to an increase of the yield of cyclic isomers. Thus, after 15 min of reaction, $75 \%$ of cyclic isomers and $15 \%$ of $9,12-$ diepoxystearic acid were formed for $90 \%$ conversion of linoleic acid against $50 \%$ of cyclic compounds after $30 \mathrm{~min}$ in the presence of 3.5 eq. of $\mathrm{H}_{2} \mathrm{O}_{2}$. In the presence of 2.5 eq. of $\mathrm{H}_{2} \mathrm{O}_{2}$, a total conversion was achieved after 30 min of reaction and 2\% yield of 9,12-diepoxystearic acid with $98 \%$ of cyclic compounds were observed. With the increase of the reaction time from $15 \mathrm{~min}$ to $30 \mathrm{~min}$, the selectivity to the desired cyclic compounds increased from $55 \%$ to $98 \%$ due to a decrease of 9,12-diepoxystearic acid yield on the benefit of the cyclic compounds showing that 9,12-diepoxystearic acid is a potential intermediate in the oxidative cleavage of linoleic acid. Moreover, an amount of 2.5 eq. of $\mathrm{H}_{2} \mathrm{O}_{2}$ prevented secondary reactions from happening and thus led to a maximum yield of $98 \%$ in cyclic isomers. However, upon prolonged reaction time $(60 \mathrm{~min})$, the cyclic isomers yield decreased due to their decomposition. Byproducts were also present throughout the reaction in the presence of 3,5 equivalents of $\mathrm{H}_{2} \mathrm{O}_{2}$ may be due to either (1) the presence of an excess of $\mathrm{H}_{2} \mathrm{O}_{2}$ which, after oxidizing the entire catalyst into active species, begins to oxidize unstable cyclic isomers into by-products, or (2) the potential degradation of the active species $\mathrm{WO}\left(\mathrm{O}_{2}\right)_{2}$ that is produced from $\mathrm{H}_{3} \mathrm{PW}_{12} \mathrm{O}_{40}$ in the presence of $\mathrm{H}_{2} \mathrm{O}_{2}$, as reported in the literature [23-25]. Hence, in the literature, it is well known that the stability of polyoxometalates in the presence of an aqueous solution of hydrogen peroxide can be an issue [22]. The degradation of cyclic isomers after $60 \mathrm{~min}$ in the presence 
of 2.5 eq. of $\mathrm{H}_{2} \mathrm{O}_{2}$ may be rationalized by the decomposition of the reaction products by excess $\mathrm{H}_{2} \mathrm{O}_{2}$ or active catalytic species after complete substrate (linoleic acid) consumption.

Table 1. Influence of the amount of hydrogen peroxide in the oxidative cyclization of linoleic acid $(1.5 \mathrm{mmol})$ in the presence of $15 \mathrm{wt} . \%$ of $\mathrm{H}_{3} \mathrm{PW}_{12} \mathrm{O}_{40}$ at $80{ }^{\circ} \mathrm{C}$.

\begin{tabular}{ccccc}
\hline $\mathrm{H}_{2} \mathrm{O}_{2}$ (eq.) & Time (min) & $\begin{array}{c}\text { Conv. } \\
(\boldsymbol{\%})\end{array}$ & $\begin{array}{c}\text { Yield of cyclic } \\
\text { comp. }(\boldsymbol{\%})\end{array}$ & $\begin{array}{c}\text { Yield of 9,12-diepoxystearic acid } \\
(\boldsymbol{\%})\end{array}$ \\
\hline \multirow{2}{*}{$\mathbf{1 . 5}$} & 60 & 60 & 39 & 21 \\
\hline \multirow{2}{*}{$\mathbf{5 . 5}$} & 15 & 90 & 75 & 15 \\
& 30 & 100 & 98 & 2 \\
\hline \multirow{3}{3.5}{} & 60 & 100 & 60 & 0 \\
\hline
\end{tabular}

In the presence of a lower amount of $\mathrm{H}_{2} \mathrm{O}_{2}$ equal to 1.5 equivalents, a maximum linoleic conversion of $60 \%$ was achieved after 60 min of reaction with the formation of maximum yields of $40 \%$ of cyclic compounds and $20 \%$ of 9,12-diepoxystearic acid. This means that this amount of $\mathrm{H}_{2} \mathrm{O}_{2}$ was insufficient to fully convert linoleic acid and 9,12-diepoxystearic acid into cyclic isomers. In summary, the use of 2.5 equivalents of $\mathrm{H}_{2} \mathrm{O}_{2}$ was optimal to achieve a total conversion of linoleic acid and a cyclic compounds yield of $98 \%$, after 30 min of reaction, with $15 \mathrm{wt} \%$ catalyst.

\subsection{Influence of catalyst amount}

The influence of the amount of catalyst was subsequently optimized. To this aim, different amount of $\mathrm{H}_{3} \mathrm{PW}_{12} \mathrm{O}_{40}$ were compared: 2 wt.\%, 5 wt.\% and 15 wt.\% (Figure 2). The reaction was performed at $80{ }^{\circ} \mathrm{C}$ in a reactor containing $1.5 \mathrm{mmol}$ of linoleic acid and 2.5 equivalents of $\mathrm{H}_{2} \mathrm{O}_{2}$. By reducing the amount of catalyst from $15 \mathrm{wt} \%$ to $5 \mathrm{wt} . \%$, the TOF increased from 1,658 to $5,570 \mathrm{~h}^{-1}$. Similar results were observed but for a longer reaction time (60 $\left.\mathrm{min}\right)$ to reach $98 \%$ of cyclic isomers yield along with $2 \%$ of 9,12-diepoxystearic acid for a total conversion 
of linoleic acid in the presence of $5 \mathrm{wt} . \%$ of $\mathrm{H}_{3} \mathrm{PW}_{12} \mathrm{O}_{40}$ catalyst. In contrast, for longer reaction time (120 min), the cyclic compounds were stable and their yield remained constant (99\%). In the presence of $5 \mathrm{wt} . \%$ catalyst, the amount of active species formed did not lead to the fragmentation of cyclic isomers after $60 \mathrm{~min}$ of reaction.

These results show that in the presence of a catalyst loading higher than $5 \mathrm{wt} . \%$ :

(1) the oxidation of the initial form of the catalyst into active species by hydrogen peroxide takes longer time than that in the presence of $5 \mathrm{wt} . \%$, which explains the decrease in TOF of the reaction. Once the entire catalyst is oxidized into active species, the latter (the active species) being more important than in the presence of $5 \mathrm{wt} \%$ catalyst, the reaction rate increases and a total conversion is achieved for a shorter reaction time;

(2) the excess of active species which still present in the reaction medium will subsequently fragment the cyclic reaction products.

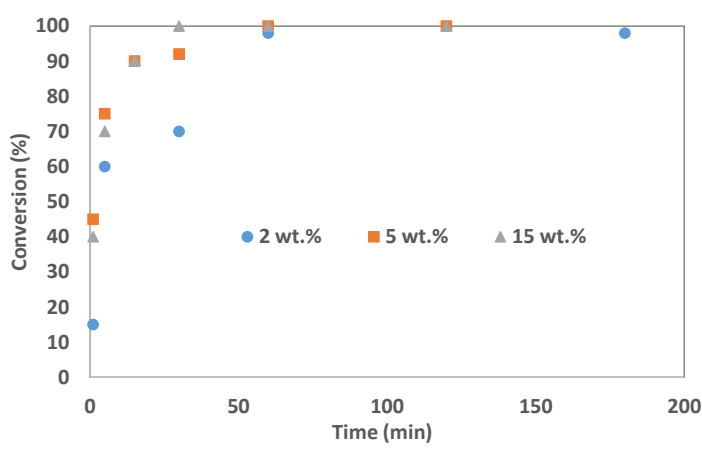

(a)

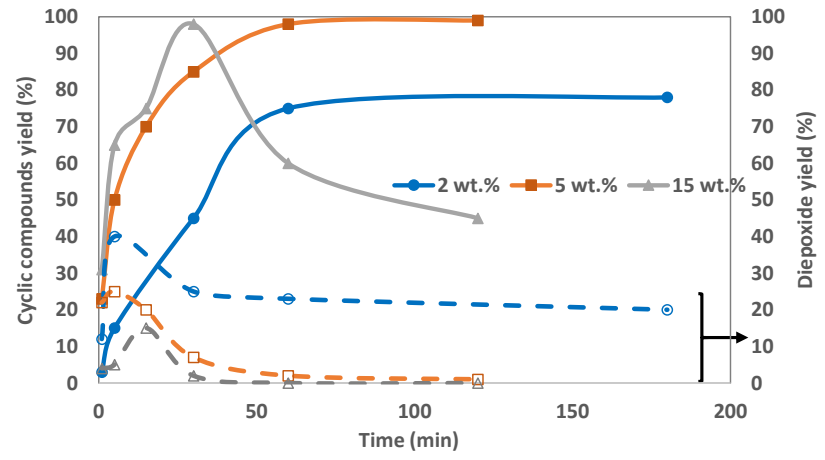

(b)

Figure 2. Influence of $\mathrm{H}_{3} \mathrm{PW}_{12} \mathrm{O}_{40}$ catalyst loading on linoleic acid (1.5 mmmol) oxidative cyclization in the presence of 2.5 eq. of $\mathrm{H}_{2} \mathrm{O}_{2}$ at $80{ }^{\circ} \mathrm{C}$. a) conversion of linoleic acid; b) cyclic compounds yield (filled lines) and 9,12-diepoxystearic acid yield (dashed lines).

A further decrease of the catalyst loading from $5 \mathrm{wt} . \%$ to $2 \mathrm{wt} . \%$ led to a conversion of $98 \%$ after $1 \mathrm{~h}$ of reaction with a decrease in the TOF from $5,550 \mathrm{~h}^{-1}$ to $4,658 \mathrm{~h}^{-1}$. This amount 
of catalyst is not sufficient to convert the entire reaction intermediate into cyclic isomers since the maximum yield in cyclic isomers formed is $75 \%$ after 60 min of reaction with $23 \%$ yield of 9,12-diepoxystearic acid. Upon prolonged reaction time, no change in the selectivity of the reaction was observed. It can be due to a decomposition of $\mathrm{H}_{2} \mathrm{O}_{2}$ at this temperature as shown below).

Therefore, an amount of $5 \mathrm{wt}$ \% catalyst is optimal to convert selectively linoleic acid into cyclic compounds ( $98 \%$ yield) without any degradation of these products.

\subsection{Influence of temperature}

The influence of temperature was finally studied (Table 2). The kinetic study was performed using $1.5 \mathrm{mmol}$ of linoleic acid in the presence of the optimal amounts of catalyst (5 wt.\% of $\left.\mathrm{H}_{3} \mathrm{PW}_{12} \mathrm{O}_{40}\right)$ and 2.5 eq. of $\mathrm{H}_{2} \mathrm{O}_{2}$.

Table 2. Influence of temperature on the oxidative cyclization of $1.5 \mathrm{mmol}$ of linoleic acid, 5 wt. $\%$ of $\mathrm{H}_{3} \mathrm{PW}_{12} \mathrm{O}_{40}$ and 2.5 eq. of $\mathrm{H}_{2} \mathrm{O}_{2}$.

\begin{tabular}{|c|c|c|c|c|}
\hline $\mathbf{T}\left(^{\circ}\right)$ & $\begin{array}{l}\text { Time } \\
(\text { min) }\end{array}$ & Conv.(\%) & $\begin{array}{l}\text { Cyclic compounds } \\
\text { Yield (\%) }\end{array}$ & $\begin{array}{c}\text { 9,12-diepoxystearic acid } \\
\text { Yield }(\%)\end{array}$ \\
\hline \multirow{4}{*}{$60{ }^{\circ} \mathrm{C}$} & 5 & 60 & 26 & 14 \\
\hline & 15 & 75 & 35 & 23 \\
\hline & 30 & 95 & 79 & 0 \\
\hline & 60 & 98 & 79 & 0 \\
\hline \multirow{4}{*}{$80{ }^{\circ} \mathrm{C}$} & 5 & 75 & 50 & 25 \\
\hline & 15 & 90 & 70 & 20 \\
\hline & 30 & 92 & 85 & 7 \\
\hline & 60 & 100 & 98 & 2 \\
\hline \multirow{4}{*}{$90{ }^{\circ} \mathrm{C}$} & 5 & 66 & 40 & 26 \\
\hline & 15 & 80 & 61 & 19 \\
\hline & 30 & 85 & 75 & 10 \\
\hline & 60 & 100 & 99 & 1 \\
\hline
\end{tabular}


At $90{ }^{\circ} \mathrm{C}$, similar results to those obtained at $80{ }^{\circ} \mathrm{C}$ were observed in terms of conversion and yields. A total conversion was achieved after 60 min of reaction with formation $99 \%$ yield of cyclic compounds and 1\% of 9,12-diepoxystearic acid.

However, by decreasing reaction temperature from 80 to $60{ }^{\circ} \mathrm{C}$, degradation products are formed even at short reaction time. A maximum yield of $80 \%$ of cyclic compounds was achieved after $30 \mathrm{~min}$ of reaction for $95 \%$ conversion of linoleic acid. The presence of degradation product at $60{ }^{\circ} \mathrm{C}$ can be due to lack of catalytic activity to convert linoleic acid to cyclic compounds. Thus, a competition could take place between the activity of the active species and the hydrogen peroxide action to linoleic acid that will decompose linoleic acid. To confirm this hypothesis, a reaction was performed in the absence of catalyst and in the presence of $1.5 \mathrm{mmol}$ of linoleic acid and 2.5 eq. of $\mathrm{H}_{2} \mathrm{O}_{2}$ at $60{ }^{\circ} \mathrm{C}$. After $60 \mathrm{~min}$ of reaction, $20 \%$ of linoleic acid was converted into non identified products. This result confirms that a temperature of $60{ }^{\circ} \mathrm{C}$ is not high enough to completely oxidize linoleic acid. In conclusion, the highest cyclic compounds yields (98\%) were obtained using 2.5 eq. of hydrogen peroxide in the presence of 5 wt. $\%$ of $\mathrm{H}_{3} \mathrm{PW}_{12} \mathrm{O}_{40}$ after $1 \mathrm{~h}$ of reaction at $80{ }^{\circ} \mathrm{C}$. Based on the effect of the temperature studied, the activation energy of this reaction was calculated based on the Arrhenius' law. The

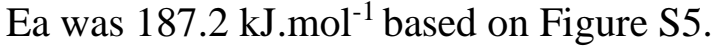

\subsection{Reaction pathways}

The oxidative cyclization of linoleic acid involves an epoxidation step of the two double bonds leading to the production of 9,12-diepoxystearic acid as an intermediate as shown before. Then hydrolysis/dehydrative cyclization of the 9,12-diepoxystearic acid occurred. One can mention that during all the experiments, no diol neither monoepoxide was detected. In the cyclization step, four pathways can occur (Scheme 6). 9,10,12,13-tetrahydroxystearic acid can be formed either in a single step by the parallel opening of the two oxirane rings of 9,12-diepoxystearic 
acid or via two steps by the opening of an oxirane ring to form the compounds A or B shown in Scheme 4. In this case, the oxirane ring of each compound (A or B) will be then opened to form the 9,10,12,13-tetrahydroxystearic acid (pathway 1 in Scheme 6). However, the formation of the 3 cyclic compounds from the two compounds A and B can also be done on a direct cyclization (pathway 2 in Scheme 6) from the reaction of a -OH group of the compound A or $\mathrm{B}$ with the oxygen of the oxirane ring. None of the two compounds ( $\mathrm{A}$ and $\mathrm{B}$ ) was detected in all reactions. One of these pathway is the opening of the oxirane rings of the epoxides to form the 9,10,12,13-tetrahydroxystearic acid (pathway 3 in Scheme 6). The different cyclic isomers will therefore be formed as a result of the interaction between two different hydroxyl groups on the carbon atoms $\mathrm{C} 9$ and $\mathrm{C} 12, \mathrm{C} 10$ and $\mathrm{C} 13$ and $\mathrm{C} 9$ and $\mathrm{C} 13$ respectively to form the cyclic compounds 1, 2 and 3 (Scheme 2). On the other hand, 9,10,12,13-tetrahydroxystearic acid was not detected in the kinetic studies so its formation is probably followed by a very rapid interaction between the different hydroxyl groups. Another route is the direct cyclization of 9,12-diepoxystearic acid which could explain that no monoepoxide neither diol was detected (pathway 4, Scheme 6). However, as a consequence, it is complex to select one of these pathways for this reaction. Further studies need to be done to understand the reaction pathway. 


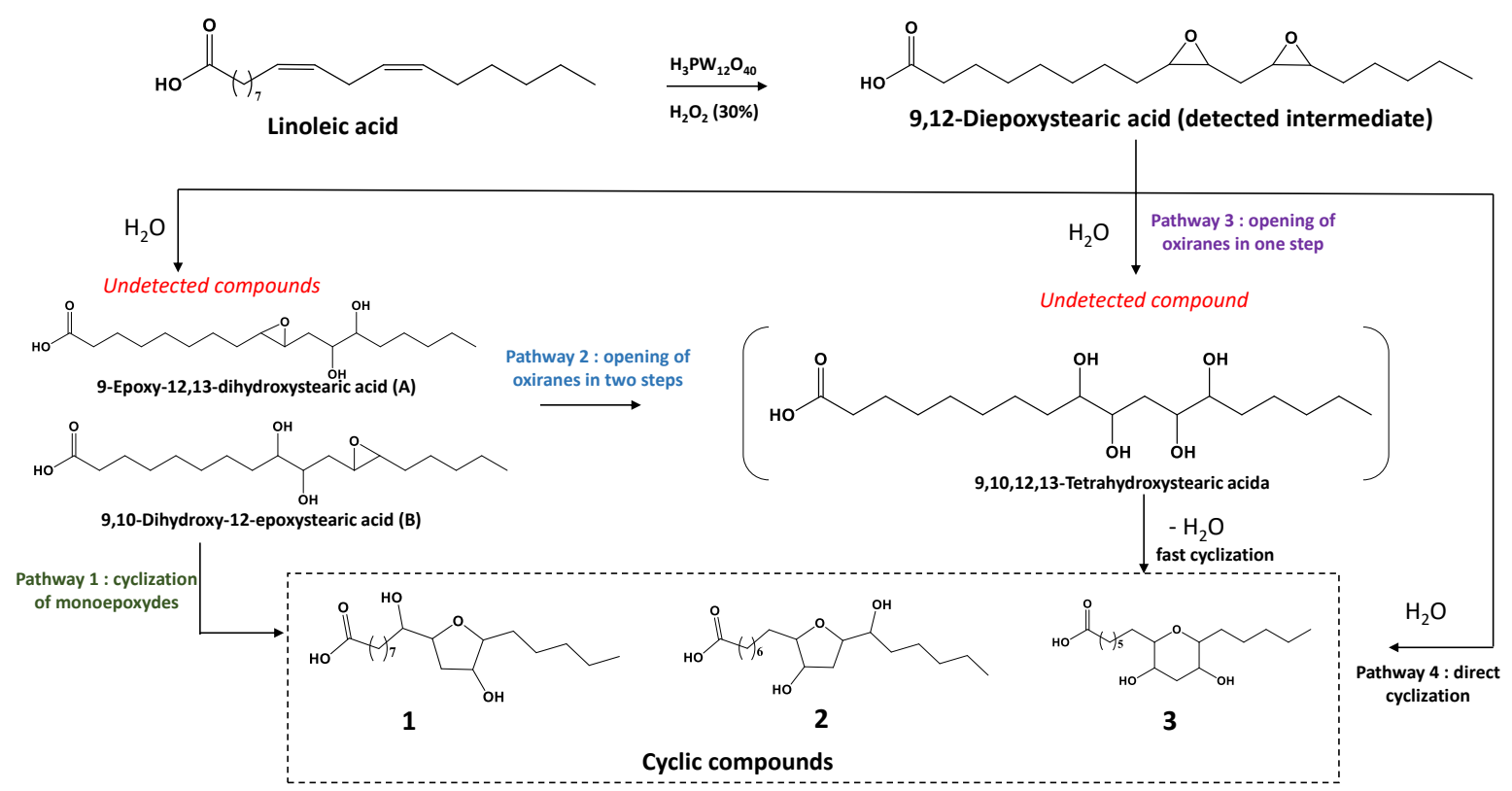

Scheme 6. Reaction pathways of the formation of cyclic isomers from linoleic acid.

\subsection{Synthesis of THF and Tetra-2H-pyrene derivatives in the presence of $\mathrm{Cs}_{2,3} \mathrm{H}_{0,7} \mathrm{PW}{ }_{12} \mathrm{O}_{40}$}

Since the homogeneous catalyst $\mathrm{H}_{3} \mathrm{PW}_{12} \mathrm{O}_{40}$, was not recyclable, a heterogeneous catalyst was synthesized, $\mathrm{Cs}_{2,3} \mathrm{H}_{0,7} \mathrm{PW}_{12} \mathrm{O}_{40}$, to study the possibility to use a recyclable catalyst in the conversion of linoleic acid into cyclic compounds. The recycling of $\mathrm{Cs}_{2,3} \mathrm{H}_{0,7} \mathrm{PW}_{12} \mathrm{O}_{40}$ was therefore performed by filtration after reaction using the following conditions: $10 \mathrm{wt} . \%$ catalyst and 2.5 equivalents of $\mathrm{H}_{2} \mathrm{O}_{2}$ at $80{ }^{\circ} \mathrm{C}$ for $2 \mathrm{~h}$ reaction (Figure 3). Under these conditions $85 \%$ of linoleic acid was converted to $60 \%$ of cyclic compounds and $25 \%$ of 9,12-diepoxystearic acid. 


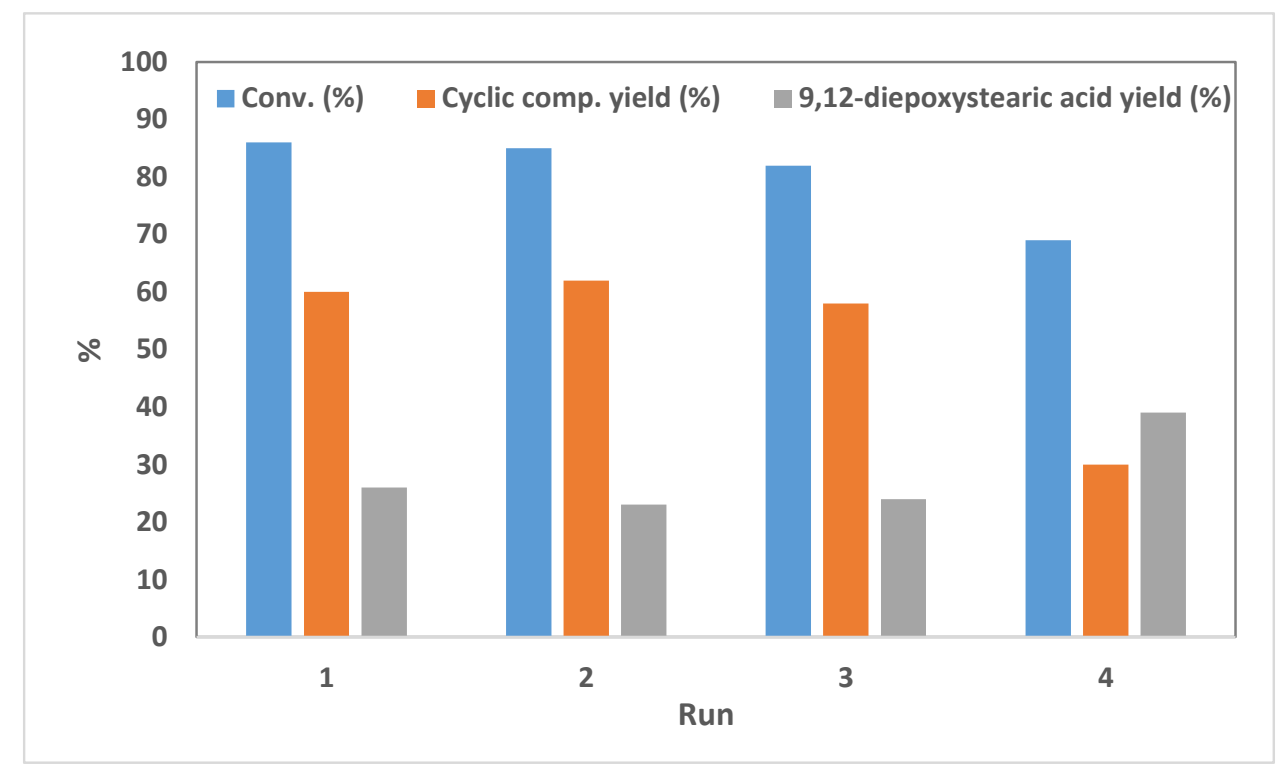

Figure 3. Recyclability of $\mathrm{Cs}_{2,3} \mathrm{H}_{0,7} \mathrm{PW}_{12} \mathrm{O}_{40}$ in the presence of $1.5 \mathrm{mmol}$ of linoleic acid, 2.5 eq. of $\mathrm{H}_{2} \mathrm{O}_{2}$ and 10 wt. $\% \mathrm{Cs}_{2,3} \mathrm{H}_{0,7} \mathrm{PW}_{12} \mathrm{O}_{40}$ at $80{ }^{\circ} \mathrm{C}$ for $2 \mathrm{~h}$ of reaction.

The results show that the heterogeneous catalyst could be recycled up to 3 times without significant loss in activity and selectivity. Similar conversions of linoleic acid (about 85\%) and constant yields to cyclic isomers (about 60\%) and 9,12-diepoxystearic acid (about 25\%) were observed. After the $4^{\text {th }}$ cycle, the catalytic efficiency of the catalyst decreased, resulting in a decrease of linoleic conversion from $85 \%$ to $69 \%$ with the formation of $30 \%$ of cyclic isomers and $35 \%$ of 9,12-diepoxystearic acid. This can be explained by a leaching of tungsten which are the active species as previously observed in our lab [26].

\section{Conclusion}

In this paper, the efficiency of the $\mathrm{H}_{3} \mathrm{PW}_{12} \mathrm{O}_{40} / \mathrm{H}_{2} \mathrm{O}_{2}$ system was studied on the oxidative cyclization of linoleic acid to substituted THF and tetrahydri-2H-pyrane. The reaction leads to the formation of three cyclic compounds that are bioactive molecules via a reaction pathway which involves 9,12-diepoxystearic acid as a reaction intermediate. Under optimal conditions a total conversion was achieved after 60 min of reaction with a yield of $98 \%$ to cyclic isomers. 
Compared to the different oxidants and catalytic systems used in the literature, the $\mathrm{H}_{3} \mathrm{PW}_{12} \mathrm{O}_{40} / \mathrm{H}_{2} \mathrm{O}_{2}$ system resulted in higher cyclic compounds yields $(98 \%)$ in the presence of a "greener" oxidant $\left(\mathrm{H}_{2} \mathrm{O}_{2}\right.$ instead of $\left.\mathrm{NaIO}_{4}\right)$ and in the absence of any phase transfer agent. Moreover, under optimal conditions the degradation of the cyclic compounds was avoided. A heterogeneous catalyst $\mathrm{Cs}_{2,3} \mathrm{H}_{0,7} \mathrm{PW}_{12} \mathrm{O}_{40}$ was synthesized and was recycled up to 3 times without significant loss of activity and yield.

\section{Acknowledgements}

The authors would like to thank the French Ministry of National Education, Higher Education and Research as well as the France-Canada Research Fund for the funding of the PhD grant of NA. The authors are also grateful to the Région Nouvelle Aquitaine for the funding of this project through the FR CNRS INCREASE 3707 (International Consortium on Eco-conception and Renewable Resources), the chair TECHNOGREEN and FEDER.

\section{Formatting of funding sources}

French Ministry of National Education, Higher Education and Research as well as the FranceCanada Research Fund for the funding of the $\mathrm{PhD}$ grant of NA.

Région Nouvelle Aquitaine (FR CNRS INCREASE 3707, TECHNOGREEN, FEDER)

\section{References}

[1] A.S. Yusuff, O.D. Adeniyi, M.A. Olutoye U. G. Akpan, A Review on Application of Heterogeneous Catalyst in the Production of Biodiesel from Vegetable Oils. J. Appl. Sci. Eng. 4 (2007). https://doi.org/10.33736/jaspe.432.2017; A. Masudi, O. Muraza, Vegetable Oil to Biolubricants: Review on

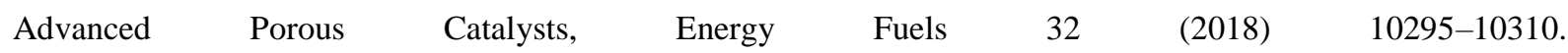
https://doi.org/10.1021/acs.energyfuels.8b02017; S. S. Sagiri, A. Anis, K. Pal, Review on Encapsulation of 
Vegetable Oils: Strategies, Preparation Methods, and Applications, Polymer-Plastics Technology and Engineering 55 (2016) 291-311. https://doi.org/10.1080/03602559.2015.1050521.

[2] A. Corma, S. Iborra, A. Velty, Chemical Routes for the Transformation of Biomass into Chemicals, Chem. Rev. 107 (2007) 2411-2502. https://doi.org/10.1021/cr050989d

[3] N. Biermann, W. Friedt, S. Lang, W. Luhs, G. Machpmuller et J.O. Metzger, New Syntheses with Oils and Fats as Renewable Raw Materials for the Chemical Industry, Angew. Chem. Int. Ed Engl. 39 (2000) $2206-2224$. https://doi.org/10.1002/1521-3773(20000703)39:13<2206::AID-ANIE2206>3.0.CO;2-P.

[4] A. Köckritz et A. Martin, Synthesis of azelaic acid from vegetable oil-based feedstocks, Eur. J. Lipid Sci. Technol. 113 (2011) 83-91. https://doi.org/10.1002/ejlt.201000117.

[5] C. J. Dutton, B. J. Banks, C. B. Cooper, Polyether lonophores. Nat. Prod. Rep. 12 (1995) 165-181. https://doi.org/10.1039/NP9951200165.

[6] L. Zeng, Q. Ye, N. H. Oberlies, G.; Shi, Z.-M. Gu, K. He, J. L. McLaughlin, Recent Advances in Annonaceous Acetogenins. Nat. Prod. Rep. 13 (1996) 275-306. https://doi.org/10.1039/NP9961300275.

[7] L. Zeng, Y. Zhang, Q. Ye, G.-E. Shi, K. He, J. L. McLaughlin, 4-deoxyannomontacin and (2,4-cis and trans)annomontacinone, new bioactive mono-tetrahydrofuran annonaceous acetogenins from Goniothalamus giganteus. Bioorg. Med. Chem. 5 (1997) 549-553. https://doi.org/10.1016/S0968-0896(96)00268-4.

[8] Q. Ye, L. Zeng, G.-E. Shi, D. Evert, J. L. McLaughlin, 4-Acetyl Annonacin and 4-Acetyl Xylomaticin: Two Novel Bioactive Mono-Tetrahydrofuran Annonaceous Acetogenins from Asimina Longifolia (Annonaceae). Nat. Prod. Lett. 8 (1996), 291-298. https://doi.org/10.1080/10575639608044910.

[9] S. Etcheverry, S. Sahpaz, D. Fall, A. Laurens, A. Cave, Annoglaucin, an acetogenin from Annona glauca. Phytochemistry 38 (1995) 1423-1426. https://doi.org/10.1016/0031-9422(94)00820-J.

[10] G.-E. Shi, L. Zeng, K. He, Q. Ye, Z.-M. Gu, J. M. MacDougal, J. L. McLaughlin, Applying Mosher's Method to Acetogenins Bearing Vicinal Diols. The Absolute Configurations of Muricatetrocin C and Rollidecins A and B, New Bioactive Acetogenins from RoUinia mucosa. Bioorg. Med. Chem. (1996) 1281-1286. https://doi.org/10.1016/0968-0896(96)00114-9.

[11] B. Travis, B. Borhan, Oxidative cyclization of 1,4-dienes to yield 2,3,5-trisubstituted tetrahydrofurandiols. Tetrahedron Letters 42 (2001) 7741-7745. https://doi.org/10.1016/S0040-4039(01)01609-4. 
[12] B. Borhan, J. Nourooz-Zadeh, T. Uematsu, B. D. Hammock, M. J. Kurth, Stereochemical aspects of cytosolic epoxide hydrolase hydration of methyl diepoxystearates. Tetrahedron 49 (1993) 2601-2612. https://doi.org/10.1016/S0040-4020(01)86339-0.

[13] T. M. Luong, H. Schriftman, D. Swern, Direct hydroxylation of fats and derivatives with a hydrogen peroxide tungstic acid system. J. Am. Oil Chem. Soc. 44 (1967) 316-320. https://doi.org/10.1007/BF02635624.

[14] E. Poli, J. Barrault, N. Bion, J. M. Clacens, Selective epoxidation of unsaturated fatty esters over peroxophosphotungstic catalysts (POW) under solvent free conditions: Study of the POW catalyst's mechanism. Catal. Today157 (2010) 371-377. https://doi.org/10.1016/j.cattod.2010.02.005.

[15] E. Santacesaria, A. Sorrentino, F. Rainone, M. Di Serio, F. Speranza, Oxidative Cleavage of the Double Bond of Monoenic Fatty Chains in Two Steps: A New Promising Route to Azelaic Acid and Other Industrial Products. Ind. Eng. Chem. Res.39 (2000) 2766-2771. https://doi.org/10.1021/ie990920u.

[16] D. Dalmizrak, H. Göksu, M. S. Gültekin, A facile synthesis of vicinal cis-diols from olefins catalyzed by in situ generated MnxOy nanoaggregates. RSC Adv. 5 (2015) 20751-20755. https://doi.org/10.1039/C5RA01646K. [17] A. Enferadi Kerenkan, F. Béland, T.-O. Do, Chemically catalyzed oxidative cleavage of unsaturated fatty acids and their derivatives into valuable products for industrial applications: a review and perspective. Catal. Sci. Technol. 6 (2016) 971-987. https://doi.org/10.1039/C5CY01118C.

[18] D. Vidal, G. Olivo, M. Costas, Controlling Selectivity in Aliphatic C-H Oxidation through Supramolecular Recognition. Chem. Eur.J. 24 (2018) 5042 -5054. https://doi.org/10.1002/chem.201704852.

[19] A. Gharib, M. Jahangir, M. Roshani, N. Noroozi Pesyan, J. Scheeren, Synthesis of (S)-(-)-Propranolol by Using $\mathrm{Cs}_{2.5} \mathrm{H}_{0.5} \mathrm{PW}_{12} \mathrm{O}_{40}$ Nanocatalyst as Green, Eco-Friendly, Reusable, and Recyclable Catalyst. Synth. React. Inorg. M. 45 (2015) 350-355. https://doi.org/10.1080/15533174.2013.832323.

[20] A. S. Dias, S. Lima, M. Pillinger, A. A. Valente, Acidic cesium salts of 12-tungstophosphoric acid as catalysts for the dehydration of xylose into furfural. Carbohydrate Research 341 (2006) 2946-2953. doi:10.1016/j.carres.2006.10.013

[21] T. Okuhara, T. Nishimura, H. Watanabe, M. J. Misono, Insoluble heteropoly compounds as highly active catalysts for liquid-phase reactions. J. Mol. Catal. 74 (1992) 247-256. https://doi.org/10.1016/03045102(92)80242-9 
[21] L. I. Kuznetsova, R. I. Maksimovskaya, M. A. Fedotov, K. I. Matveev, Peroxo complexes of phosphotungstic heteropoly acid. Russ Chem Bull 32 (1983) 666-670. https://doi.org/10.1007/BF00953453.

[23] L. Carlos de la Garza, K. De Oliveira Vigier, G. Chatel, A. Moores, Amphiphilic dipyridiniumphosphotungstate as an efficient and recyclable catalyst for triphasic fatty ester epoxidation and oxidative cleavage with hydrogen peroxide. Green Chem. 19 (2017) 2855-2862. https://doi.org/10.1039/C7GC00298J.

[24] J.-E.Bäckvall, Modern Oxidation Methods, Wiley-VCH Verlag GmbH \& Co. KGaA, 2004. DOI:10.1002/3527603689

[26] $\mathrm{PhD}$ thesis of Nahla Araji, Procédé éco-compatible d'oxydation catalytique de molécules biosourcées insaturées (furfural, esters ou acides gras insaturés), 2018. 